\title{
Pulmonary complications of HIV disease: 10 year retrospective evaluation of yields from bronchoalveolar lavage, 1983-93
}

Ian K Taylor, Richard J Coker, John Clarke, Fiona M Moss, Richard Nieman, David J Evans, Daniel Veale, Rory J Shaw, Douglas S Robinson, David M Mitchell

\begin{abstract}
Background - Pulmonary disease is a major contributor to morbidity and mortality in patients with HIV infection and AIDS. The aim of this study was to describe bronchoscopic findings and the spectrum of pulmonary pathogens in HIV seropositive patients undergoing investigation of respiratory disease over a 10 year period in a major UK referral centre. Methods - Recruitment was procedure based with data being captured when bronchoscopy was clinically indicated. Data were evaluated from 580 HIV seropositive patients (559 men, age 13-65 years) over a 10 year period from June 1983 to March 1993.
\end{abstract}

Results - A total of 947 bronchoscopies was performed. The most frequent pulmonary pathogen isolated from bronchoalveolar lavage (BAL) fluid in $44 \%$ of all bronchoscopies was Pneumocystis carinii. Of all patients studied, $324(55 \%)$ had at least one cytologically confirmed episode of $P$ carinii pneumonia; this was AIDS defining in $219(38 \%)$ of patients who underwent bronchoscopy. Between 1987 and 1993 the overall diagnostic yield from BAL fluid was $76 \% ; 25 \%$ of all bronchoscopies yielded positive microbiological results, the most frequent isolates being Staphylococcus aureus, Streptococcus pneumoniae, Pseudomonas spp, and Haemophilus influenzae. Mycobacteria were identified in $8 \%$ of patients; $M$ tuberculosis was the most common being identified in $3 \%$ of lavage samples and in $4 \%$ of patients. No drugresistant $M$ tuberculosis was found. Viral isolates (mainly cytomegalovirus) were identified in up to $31 \%$ of BAL fluid samples. Endobronchial Kaposi's sarcoma was seen in $15 \%$ of patients at bronchoscopy.

Conclusions - Of the 1956 newly diagnosed HIV seropositive patients receiving clinical care at St Mary's Hospital over this period, approximately $30 \%$ underwent bronchoscopy. Diagnostic rates for $\boldsymbol{P}$ carinii pneumonia, endobronchial Kaposi's sarcoma, and bacterial and mycobacterial infection have remained largely constant since 1989. Bronchoalveolar lavage produces high diagnostic yields generally, and $\boldsymbol{P}$ carinii pneumonia remains a common cause of pulmonary disease in these patients.

(Thorax 1995;50:1240-1245)

Keywords: HIV infection, Pneumocystis carinii pneumonia, bronchitis, AIDS

The pulmonary complications of HIV disease are now well recognised and described. Considerable uniformity in the diagnostic approach has evolved in which fibreoptic bronchoscopy, coupled with bronchoalveolar lavage (BAL), has become routine..$^{1-10}$

During the 10 year period from January 1983 to March 19931956 patients with HIV disease, including 914 with AIDS, have received their regular clinical management at St Mary's Hospital, Paddington, London, a large HIV referral centre. The aim of this study was to evaluate by retrospective analysis the diagnostic yields and the spectrum of pulmonary pathogens obtained by fibreoptic bronchoscopy and BAL in HIV seropositive patients with respiratory symptoms for the 10 year period June 1983 to March 1993.

\section{Methods}

PATIENTS

Between June 1983 and the end of March 1993 $580 \mathrm{HIV}$ seropositive patients ( $559 \mathrm{men}$ ) aged 13-65 years underwent fibreoptic bronchoscopy for investigation of respiratory symptoms. The indications for bronchoscopy were new respiratory symptoms of several days duration (cough or breathlessness), often associated with systemic features (fever, lassitude, or weight loss), and an abnormality in pulmonary physiology (reduced carbon monoxide transfer factor) or chest radiology.

Following clinical evaluation fibreoptic bronchoscopy was performed within 48 hours except in patients considered too ill for the procedure. The decision to perform a bronchoscopy did not delay starting treatment for either Pneumocystis carinii pneumonia or for a bacterial pneumonia if these were thought on clinical grounds to be the most likely diagnoses.

\section{BRONCHOSCOPY AND BRONCHOALVEOLAR}

LAVAGE (BAL)

Fibreoptic bronchoscopy was performed in standard fashion. Arterial oxygen saturation 
was monitored and supplemental oxygen delivered as required. After segmental and subsegmental inspection to evaluate the presence of endobronchial Kaposi's sarcoma, the bronchoscope was wedged in the medial segment of the middle lobe or in the segmental bronchus corresponding to the area of maximal radiographic abnormality. Bronchoalveolar lavage was performed by instillation of up to four sequential $60 \mathrm{ml}$ aliquots of sterile isotonic saline warmed to $37^{\circ} \mathrm{C}$ and then removed under low pressure and pooled in a $500 \mathrm{ml}$ polypropylene bottle. All BAL specimens were evaluated for bacteria, fungi, and mycobacteria by conventional microbiological techniques, for viruses by cell culture and, in some cases, by immunofluorescent identification of specific viruses and for detection of cytomegalovirus by detection of early antigen fluorescent foci (DEAFF). The presence of $P$ carinii was determined by Giemsa and Grocott stains on direct smears and cytospin preparations. Apart from the introduction of immunofluorescent techniques for viral identification in the last three years, there have been few changes in the diagnostic techniques employed during the period of study. In a limited number of cases, transbronchial or endobronchial biopsy was performed.

\section{SOURCES OF DATA}

Patients who underwent bronchoscopy were identified from records kept in the endoscopy suite. Demographic details including sex and date of birth, risk factors for the acquisition of HIV, date of AIDS defining diagnosis, and the AIDS defining diagnosis were obtained from patient case records and from a computerised data base. In those patients in whom endobronchial Kaposi's sarcoma was diagnosed at bronchoscopy, hospital case records were

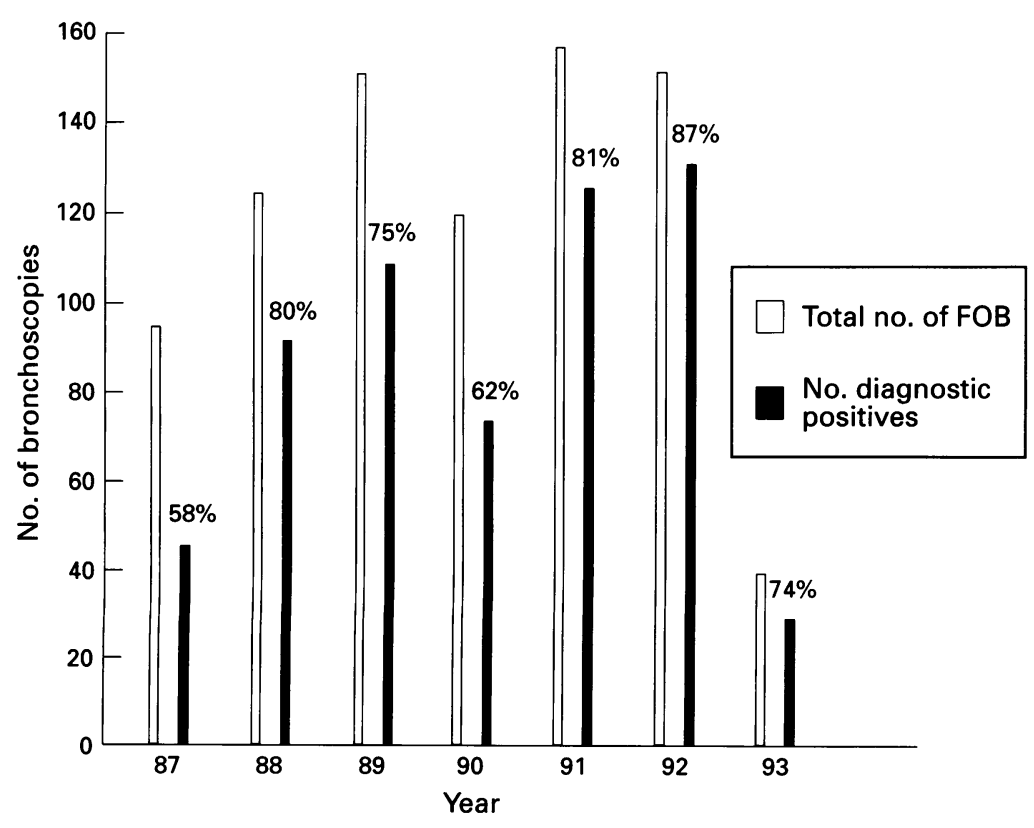

Figure 1 Total diagnostic yield from fibreoptic bronchoscopy (FOB) and bronchoalveolar lavage from fanuary 1987 to March 1993 showing both the absolute number and the percentage of diagnostic positives. searched to evaluate the presence and date of any antecedent extrapulmonary Kaposi's sarcoma. Individual cytological, microbiological, virological, and mycobacteriological results were obtained from the respective laboratory departments and supplemented where necessary from the case notes.

\section{TREATMENT}

Throughout the study period there have been some changes in both the prophylaxis and treatment of major opportunistic infections. P carinii pneumonia has been treated throughout the 10 year period in our unit with high dose cotrimoxazole as first line treatment, and dapsone and trimethoprim (or more recently clindamycin and primaquine) if intolerance occurs. Short courses of high dose corticosteroids were introduced in 1990 as adjunctive therapy in patients with $P$ carinii pneumonia with respiratory failure. Since 1988 secondary prophylaxis has been offered to patients (fortnightly nebulised pentamidine, thrice weekly co-trimoxazole, or thrice weekly dapsone and pyrimethamine). Since 1989 primary prophylaxis has been offered to all patients with CD4 counts of $<200 / \mathrm{mm}^{3}$ or with symptoms of HIV disease. CD4 counts were not available in all patients in this study and these data are not included. In 1987 patients with AIDS were offered zidovudine if clinically appropriate. Since 1987, by which time patient numbers had rapidly increased, the indications for diagnostic bronchoscopy are not considered to have changed substantially.

\section{Results}

Between June 1983 and March 1993580 patients known to be HIV seropositive underwent diagnostic bronchoscopy. Their ages ranged from 13 to 65 years and most $(92 \%)$ were homosexual or bisexual men. During this period 1956 patients with HIV disease, including 914 with AIDS, have received their regular clinical management at this hospital; approximately $30 \%$ of these patients underwent bronchoscopy at some stage in their clinical course and a total of 947 bronchoscopies was performed. Of the 580 patients who had bronchoscopy, 343 had the procedure performed once, 144 twice, 65 three times, 21 on four occasions, six on five occasions, and one patient more than five times. There was a rapid increase in the number of HIV cases in 1987 at which time clinical practice was standardised. The total diagnostic yield from bronchoscopy expressed both in absolute and percentage terms from 1987 to 1993 is illustrated in fig 1 . For the period 1987-93 a positive overall diagnosis was made from the results of bronchoscopy in $76 \%$ of cases, although annual rates varied between $58 \%$ and $87 \%$. Annual yields from $\mathrm{BAL}$ in individual diagnostic categories are shown in fig 2. Diagnostic yield was taken as the number of bronchoscopies with a positive laboratory finding divided by the total number of bronchoscopies performed. 


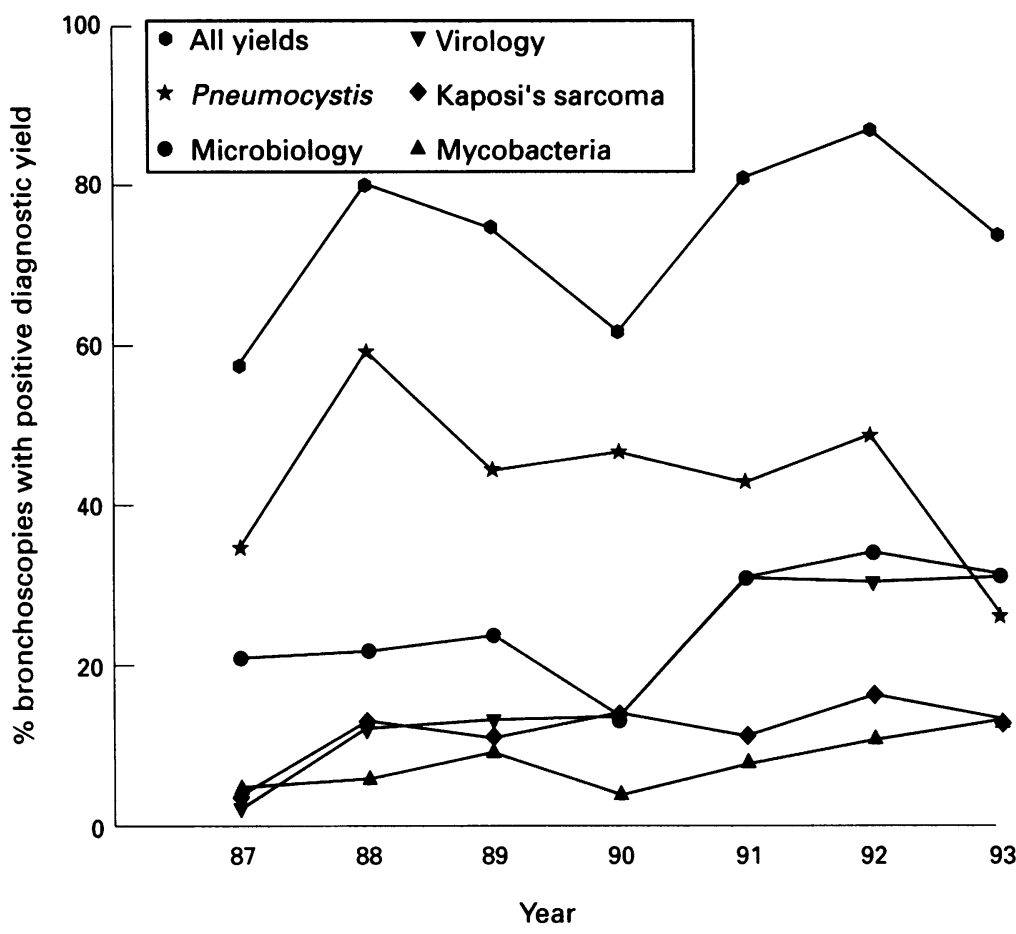

Figure 2 Annual percentage of bronchoscopies yielding positive diagnoses delineated by diagnostic category, the 1993 data relate only to the first three months.

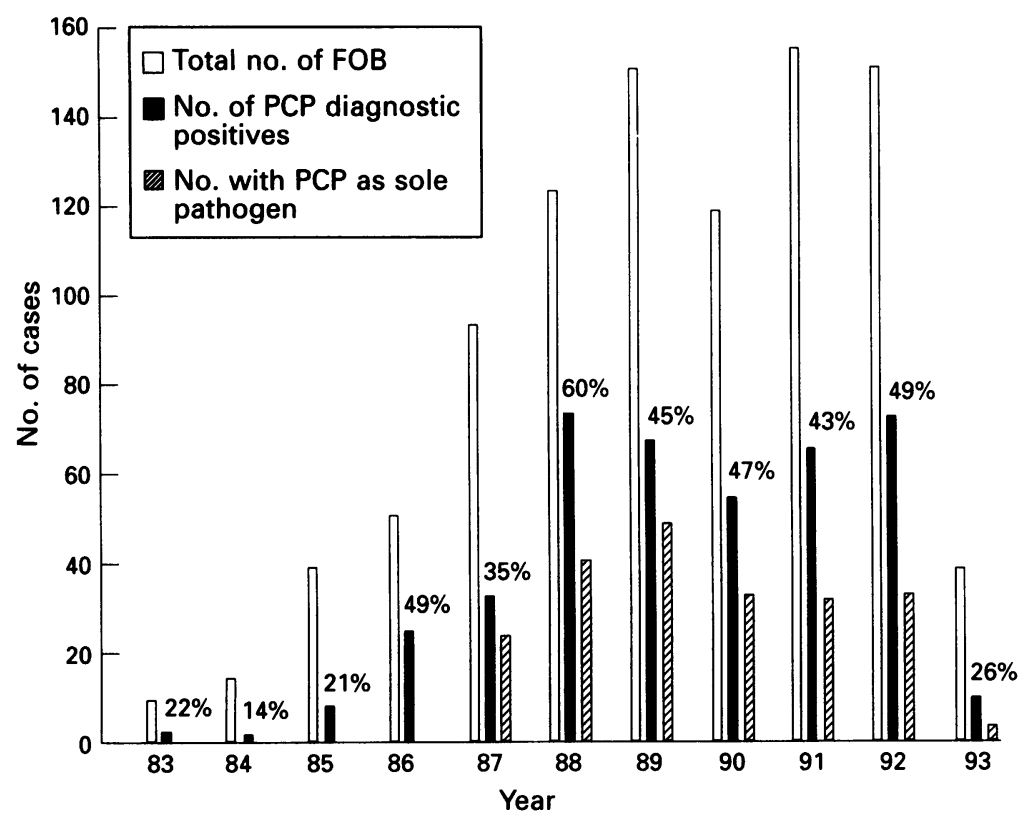

Figure 3 Diagnostic yield from fibreoptic bronchoscopies (FOB) with bronchoalveolar lavage for Pneumocystis carinii pneumonia (PCP) from fune 1983 to March 1993 showing both the absolute number and the percentage of diagnostic positives. The number of bronchoscopies with Pneumocystis carinii as the sole isolated pathogen between 1983 and 1986 is not shown. proven episode of $P$ carinii pneumonia; amongst these patients this was AIDS defining in $219(68 \%)$ cases. Seventy six patients had two or more episodes of $P$ carinii pneumonia.

Of the 324 new cases of $P$ carinii pneumonia diagnosed bronchoscopically between 1983 and 1993 there were 26 deaths (8\%) during the acute episode (within one month of diagnosis). Between 1987 and 1993, of the 288 newly diagnosed cases of pneumocystis pneumonia during that time there have been only 13 deaths within one month of bronchoscopy $(4.5 \%)$. Of these 13 patients, five had no other associated pulmonary disease diagnosed bronchoscopically. Of the remainder, two had coexistent Kaposi's sarcoma, four had associated viral pathology (two cytomegalovirus, one adenovirus, one herpes), and two had pyogenic infection with Pseudomonas spp, of which one also had a high grade endobronchial non-Hodgkin's lymphoma.

\section{MICROBIOLOGY}

The percentage of bronchoscopies yielding positive bacterial culture varied annually between $21 \%$ and $34 \%$ with a mean of $25 \%$. Staphylococcus aureus, Streptococcus pneumoniae, Pseudomonas $\mathrm{sp}$, and Haemophilus influenzae were the organisms most commonly isolated, being found in $56(6.7 \%), 42(5.0 \%), 31$ $(3.7 \%)$, and $29(3.5 \%)$, respectively of the 834 bronchoscopies performed between 1987 and 1993. Whether these isolates were pathogenic in all cases is uncertain. Amongst isolates of Staph aureus $(\mathrm{n}=56)$ it was the sole isolate in only 13 cases; in 29 of the remaining 43 cases it was found in association with either $P$ carinii or Kaposi's sarcoma (or both).

Fungal isolates in BAL fluid were found in 83 instances of which Candida spp were clearly predominant $(n=67)$ but of unlikely clinical significance. Pulmonary isolates of Aspergillus spp were rare $(n=9)$, as were those of Cryptococcus $\operatorname{spp}(\mathrm{n}=3)$. In one patient, a resident in the USA, Histoplasma capsulatum was isolated on two occasions.

\section{MYCOBACTERIA}

Between 1987 and 1993 mycobacteria were isolated in 63 of $834(7.5 \%)$ samples of $\mathrm{BAL}$ fluid with annual prevalence rates between $5 \%$ and $13 \%$. Of the mycobacterial pathogens isolated, $M$ tuberculosis was the commonest, occurring in 23 of 834 samples of BAL fluid $(2 \cdot 8 \%)$ and from 22 of the 497 patients $(4 \cdot 4 \%)$. No drug-resistant organisms were observed amongst these isolates. Four of the patients had culture positive evidence of extrapulmonary tuberculosis.

The remaining mycobacterial isolates $(\mathbf{n}=$ 40) were atypical non-tuberculous mycobacteria obtained from 39 lavage samples $(5 \%)$ and from 36 patients (7\%). Of these, $M$ xenopi was most commonly isolated (in 17 patients) followed by $M$ avian intracellulare in 14 . 


\section{VIROLOGY}

Cytomegalovirus (CMV) was the principal virus with yields from bronchoscopic examination having increased in the last three years of the study, probably as a result of improved cell culture techniques and introduction of the DEAFF test. CMV was identified overall in $132(16 \%)$ of BAL samples. In a nested study over the period April 1989 to January 1992 detection of CMV in BAL fluid by polymerase chain reaction (PCR) was compared with standard cell culture techniques. Of the 68 samples of BAL fluid utilised for both sets of analysis, CMV was identified using PCR in $33(49 \%)$ and by conventional analysis in nine $(13 \%)$. All the latter cases were identified by PCR. Other viruses identified in BAL fluid were: adenovirus in eight, $\mathrm{HSV}$ in 14, parainfluenzae III in four, and influenza B in two.

\section{ENDOBRONCHIAL KAPOSI'S SARCOMA}

Endobronchial Kaposi's sarcoma was categorised as local if lesions were confined to the wall of the trachea or involved a segmental bronchus of a single lobe, or extensive if lesions involved both the tracheal wall and a segmental bronchus of a single lobe or two or more lobes. The total number of patients with bronchoscopically visualised local or extensive Kaposi's sarcoma over the period 1987-93 was 74 , representing an incidence of $15 \% ; 73$ of these patients were homosexual or bisexual men. A biopsy sample was only taken if there was either clinical or histological doubt regarding the diagnosis at other more accessible sites, hence in only five cases was endobronchial Kaposi's sarcoma confirmed by biopsy and in a further two cases histological appearances were equivocal.

In 26 patients the initial unequivocal bronchoscopic appearance of Kaposi's sarcoma was evaluated as local disease, and in 48 as extensive. No records on the absence or presence of extrapulmonary Kaposi's sarcoma or its temporal relationship to pulmonary Kaposi's sarcoma were available in nine of the 74 patients. In 61 of the remaining 65 patients there was documented diagnostic evidence of preceding extrapulmonary Kaposi's sarcoma - cutaneous, visceral, lymphatic, or palatal. In the remaining four patients pulmonary Kaposi's sarcoma was AIDS defining in two, with other manifestations of the tumour appearing within one month, and in the other two patients local presentations of pulmonary Kaposi's sarcoma were the first presentation of the tumour but these were not AIDS defining.

In the 18 patients who had more than two successive bronchoscopies who had endobronchial Kaposi's sarcoma (all of whom had received chemotherapy), in only two did endobronchial Kaposi's sarcoma regress macroscopically. In the other 16 patients endobronchial lesions remained stable or progressed. Of the 101 bronchoscopies performed between 1987 and 1993 in which endobronchial Kaposi's sarcoma was unequivocally observed (representing an overall procedure incidence of $12 \%$ ), it was the sole positive finding in 33 and presumably accounted exclusively for the pulmonary features in these patients at that time. In 26 of the remaining 68 procedures, and in 19 patients, Kaposi's sarcoma was associated with evidence of $P$ carinii pneumonia in the BAL fluid.

ENDOBRONCHIAL/TRANSBRONCHIAL HISTOLOGY Since 1987 transbronchial biopsies were taken in 191 of 834 (23\%) bronchoscopies. There was a fall in biopsy rate over the period of study from $54 \%$ in 1987 to $7 \%$ in 1992 . Most of the biopsies reinforced the diagnostic information obtained from BAL fluid and in only nine cases did they yield additional information (five cases of lymphoid interstitial pneumonia, two cases of non-Hodgkin's lymphoma, and two cases of $P$ carinii pneumonia).

\section{Discussion}

This study aimed to evaluate bronchoscopic findings and diagnostic yields in HIV seropositive patients and how these may have changed with time. Unlike other studies where patient enrollment had strict inclusion criteria, recruitment to this study was procedure based, which introduces bias, yet the purpose of this study was to evaluate the clinical usefulness of bronchoscopy in this setting. ${ }^{11-15}$ Data were captured for all patients at points in their clinical course when bronchoscopy was considered appropriate on clinical, radiographic, or physiological grounds. This approach is open to criticism as the bronchoscopic findings were not prospectively evaluated in conjunction with clinical indices of disease progression, regression, specific therapeutic intervention, or outcome but, as already stated, the aim of this study was simply to evaluate the clinical usefulness of bronchoscopy in routine clinical practice. Furthermore, a general problem with all clinical studies of diagnostic yields for $P$ carinii pneumonia by bronchoscopy is the case definition. As confirmatory open lung biopsies or necroscopic examinations are rarely available, the denominator will always include unconfirmed cases that were clinically typical, responded appropriately to specific therapy, and where no alternative diagnosis emerged. A problem with this is that cases of pneumonia responsive to co-trimoxazole may include some bacterial cases.

Bearing these reservations in mind, most bronchoscopic studies previously reported ${ }^{11-15}$ were conducted during the early years of the HIV epidemic and contained data on fewer patients than the present study. The larger previous studies ${ }^{114}$ have shown both the high diagnostic accuracy and sensitivity and the high negative predictive value (or low false negative rate) of both BAL and transbronchial biopsy. This study confirms previous observations that $P$ carinii pneumonia is still the most important pulmonary complication. Our findings also support the limited additional information obtained by transbronchial biopsy. ${ }^{1-14}$ Finally, our overall frequency of isolation of pulmonary pathogens from BAL fluid is in line with 
others $^{14}$ at $76 \%$, although annual trends did fluctuate.

Over the last 10 years $P$ carinii has been identified in respiratory tract specimens in 55\% of all HIV seropositive patients undergoing bronchoscopy, providing the index AIDS defining diagnosis in 219 (38\%) of these patients. For the last seven completed years (1986-93) between $35 \%$ and $60 \%$ of all bronchoscopies annually were positive for $P$ carinii pneumonia (fig 3) with a mean of $47 \%$, and over the last four years (1989-92) there has been no trend towards a decline, despite widespread use of zidovudine and prophylaxis, which confirms a similar recent observation. ${ }^{16}$

Bacterial infections are common in HIV infected patients. ${ }^{17}$ In an early series, Murray et $a l^{1}$ reported that $2.5 \%$ of patients with HIV pulmonary disorders had bacterial infection. In the current study, largely of homosexual or bisexual men containing very few intravenous drug abusers, although Str pneumoniae and $H$ influenzae were common, it is interesting that Staph aureus was the most common bacterial isolate. In several studies Staph aureus has not been reported as a frequent cause of pneumonia ${ }^{16-19}$ whereas other series have reported staphylococcal pneumonia in HIV disease in up to $8 \%,{ }^{20-22}$ often occurring in association with pulmonary Kaposi's sarcoma or $P$ carinii pneumonia - observations which our data support.

Our data also suggest a trend towards an increase in bacterial yields from BAL fluid over the study period, an observation in line with that of Pitkin et al. ${ }^{16}$ However, these yields may be an underestimation due to antibiotic therapy before bronchoscopy. This study emphasises that fungal infection is rare. The frequent isolation of Candida is almost certainly not of clinical relevance. It is interesting to note that there were only slight differences in the characteristics of fungal isolates (other than Candida spp) compared with the previously reported large North American series. ${ }^{114}$

A recent study identified that, in patients with AIDS in England and Wales, $4.6 \%$ also had tuberculosis. ${ }^{23}$ During two survey periods (1983 and 1988) of tuberculosis notifications only one and nine patients, respectively, were known to be infected with HIV, suggesting that HIV infection has not yet had an appreciable impact on tuberculosis notifications. Another study ${ }^{24}$ reported a $6 \%$ incidence of both pulmonary and extrapulmonary tuberculosis in patients with HIV infection and, in contrast to data from urban centres in the USA, ${ }^{25}$ almost no primary drug resistance. In this study we observed a small increase in isolates of $M$ tuberculosis from BAL fluid during the last 2-3 years. $M$ tuberculosis was isolated in only $3 \%$ of bronchoscopies between 1987 and 1993 and in $4 \%$ of patients, emphasising that so far there is little overlap between pulmonary tuberculosis and proven seropositive HIV status in London and that, as yet, multidrug-resistant isolates of $M$ tuberculosis have not occurred, in contrast to the situation with AIDS in Africa or intravenous drug users with AIDS in New York.

Current evidence suggests that CMV in the lung of patients with AIDS does not cause disease, nor does its presence adversely affect survival. ${ }^{26-30}$ Our isolation rates of CMV from BAL fluid were low compared with other series, ${ }^{1426}$ including a small series of our own ${ }^{28}$ in which CMV was detected in BAL fluid by PCR. This was probably due to inadequacies in cell culture techniques which, when rectified, resulted in increased viral yield.

Intrathoracic Kaposi's sarcoma may account for pulmonary disease in patients with HIV infection. ${ }^{31}$ Whilst Kaposi's sarcoma occurs in up to $25 \%$ of all patients with AIDS, ${ }^{32}$ the incidence of pulmonary manifestations has been variably reported at between $3 \%$ and $13 \%$ of patients with AIDS, ${ }^{133}$ in up to $32 \%$ of patients with AIDS and cutaneous Kaposi's sarcoma, ${ }^{33-35}$ and in approximately $10 \%$ of patients with AIDS and respiratory symptoms. ${ }^{136}$ In two further recent clinical studies the incidence of endobronchial Kaposi's sarcoma in HIV patients was, respectively, quoted at $8 \%^{37}$ and $13 \%^{38}$ although, by contrast, bronchopulmonary Kaposi's sarcoma has been found at necropsy in $47 \%$ of patients with AIDS who had cutaneous manifestations of the tumour. $^{39}$

The incidence of bronchoscopically visualised endobronchial Kaposi's sarcoma between 1987 and 1993 was 15\% amongst all patients and $12 \%$ amongst all procedures, with annual rates since 1988 fluctuating between $10 \%$ and $16 \%$. Almost all patients with endobronchial Kaposi's sarcoma had evidence of extrapulmonary disease.

The final point to address relates to trends in workload with respect to patient requirements for bronchoscopy, and the implications that this may have for future health care provision and resource planning. Our data suggest that at least $30 \%$ of all patients with HIV infection will, at some stage, need a bronchoscopy.

In conclusion, this retrospective analysis presents data from a 10 year period in patients with HIV infection who received their clinical care at a principal UK referral centre. The data reflect routine respiratory clinical practice and the findings are purely descriptive, based on routine laboratory analysis of BAL fluid obtained at bronchoscopy. Our analysis over time has allowed some observations of minor trends in the important pulmonary diagnostic categories within the spectrum of HIV infection. Such data acquisition is important in defining future health care needs, clinical care supervision, and research priorities.

1 Murray JF, Felton CP, Garay SM, Gottlieb MS, Hopewell PC, Stover $\mathrm{E}$, et al. Pulmonary complications of the PC, Stover E, et al. Pulmonary complications of the acquired immuno

2 Hopewell PC, Luce JM. Pulmonary involvement in the acquired immunodeficiency syndrome. Chest 1985;87: acquired

3 Stover DE, White DA, Romano PA, Gellene RA, Robeson WA. Spectrum of pulmonary diseases associated with the acquired immune deficiency syndrome. Am f Med 1985; 78:429-37.

4 Murray JF, Garay SM, Hopewell PC, Mills J, Snider GL, Stover DE. Pulmonary complications of the acquired immunodeficiency syndrome: an update. Am Rev Respir Dis 1987;135:504-9.

5 Murray JF, Mills J. Pulmonary complications of human immunodeficiency virus infection: part 1. Am Rev Respir Dis 1990;141:1356-72. 
6 Murray JF, Mills J. Pulmonary complications of human immunodeficiency virus infection: part 2. Am Rev Respir Dis 1990;141:1582-98.

7 Mitchell DM. Pulmonary complications of AIDS. In: Mitchell DM, ed. Recent advances in respiratory medicine. Churchill Livingstone, 1991:125-46.

8 Miller RF, Mitchell DM. Pneumocystis carinii pneumonia. Thorax 1992;47:305-14.

9 Mitchell DM, Miller RF. Recent developments in the management of the pulmonary complications of HIV disease. Thorax 1992;47:381-90.

10 Agostini C, Trentin L, Zambello R, Semenzato G. HIV-1 and the lung. Am Rev Respir Dis 1993;147:1038-49.

11 Coleman DL, Dodek PM, Luce JM, Golden JA, Gold WM, Murray FJ. Diagnostic utility of fibreoptic bronchoscopy in patients with Pneumocystis carinii pneumonia and the acquired immunodeficiency syndrome. Am Rev Respir Dis 1983;128:795-9.

12 Stover DE, White DA, Romano PA, Gellene RA. Diagnosis of pulmonary disease in acquired immunodeficiency syndrome. Am Rev Respir Dis 1984;130:659-62.

13 Ognibene FP, Shelhamer J, Gill V, Macher AB, Loew D, Parker MM, et al. The diagnosis of Pneumocystis carini pneumonia in patients with the acquired immunodeficiency syndrome using subsegmental bronchoalveolar lavage. Am Rev Respir Dis 1984;129:929-32.

14 Broaddus C, Dake MD, Stulbarg MS, Blumenfeld W, Hadley WK, Golden JA, et al. Bronchoalveolar lavage and transbronchial biopsy for the diagnosis of pulmonary infections in the acquired immunodeficiency syndrome. Ann Intern Med 1985;102:747-52.

15 Warren JB, Shaw RJ, Weber JN, Holt DA, Keal EE, Pinching AJ. Role of fibreoptic bronchoscopy in management of pneumonia in acquired immunodeficiency syndrome. BMF 1985;291:1012-3.

16 Pitkin AD, Grant AD, Foley NM, Miller RF. Changing patterns of respiratory disease in HIV positive patients in a referral centre in the United Kingdom between 1986-7 a referral centre in the United Kingdom $1990-1$. Thorax 1993;48:204-7.

17 Witt DJ, Craven DE, McCabe WR. Bacterial infections in adult patients with the acquired immunodeficiency syndrome (AIDS) and AIDS-related complex. $A m \mathcal{f} \mathrm{Med}$ 1987;82:900-6.

18 Polsky B, Gold JWM, Whimbey E, Dryjanski J, Brown AE, Schiffman G, et al. Bacterial pneumonia in patients with the acquired immunodeficiency syndrome. Ann Intern Med 1986;104:38-41.

19 Murata GH, Ault MJ, Meyer RD. Community acquired bacterial pneumonias in homosexual men: presumptive
evidence for a defect in host resistance. AIDS Res 1984; 1:379-93.

20 Nichols L, Balogh K, Silverman M. Bacterial infections in the acquired immunodeficiency syndrome. Clinicopathologic correlations in a series of autopsy cases. $A m \mathcal{F}$ Clin Pathol 1989;92:787-90.

21 Eng RHK, Bishburg E, Smith S, Geller H, Kapila R. Bacteremia and fungemia in patients with acquired immune deficiency syndrome. Am 7 Clin Pathol 1986;86: 105-7.

22 Whimbey E, Gold JWM, Polsky B, Dryjanski J, Hawkins $\mathrm{C}$, Blevins A, et al. Bacteremia and fungemia in patients
with the acquired immunodeficiency syndrome. Ann Intern with the acquired immun $1986 ; 104: 511-4$.
23 Watson JM, Meredith SK, Whitmore-Overton E, Bannister B, Darbyshire JH.'Tuberculosis and HIV: estimates of the overlap in England and Wales. Thorax 1993;48:199-203.

24 Helber M, Robinson D, Buchanan D, Hellyer T, McCarty M, Brown I, et al. Mycobacterial infection in patients infected with the human immunodeficiency virus. Thorax 1990;45:45-8.

25 Freiden TR, Sterling T, Pablos-Mendez A, Kilburn JO, Cauthen GM, Dooley SW. The emergence of drug resistant tuberculosis in New York City. $N$ Engl f $M e d$ 1993;328:521-6.

26 Miles PR, Baughman RP, Linnemann CC. Cytomegalovirus in the bronchoalveolar lavage fluid of patients with AIDS Chest 1990;97:1972-6.

27 Millar AB, Patou G, Miller RF, Grundy JE, Katz DR, Weller IV, et al. Cytomegalovirus in the lungs of patients with AIDS: respiratory pathogen or passenger? Am Rev Respir Dis 1990;141:1474-7.

28 Clarke JR, Fleming J, Donegan K, Moss FM, Nieman R, Williamson JD, et al. Effect of HIV-1 on cytomegalovirus in bronchoalveolar lavage cells on the transfer factor for lung carbon monoxide in AIDS patients. AIDS 1991;5: 1338-8.

29 Bower M, Barton SE, Nelson MR, Bobby J, Smith D, Youle $M$, et al. The significance of the detection of cytomegalovirus in the bronchoalveolar lavage fluid in AIDS patients with pneumonia. AIDS 1990;4:317-20.

30 Jacobsen MA, Mills J, Rush J, Peiperl L, Seru V, Mohanty PK, et al. Morbidity and mortality of patients with AIDS and first episode Pneumocystis carinii pneumonia unaffected by concomitant pulmonary cytomegalovirus infection. Am Rev Respir Dis 1991;144:6-9.

31 White DA, Matthay RA. Non-infectious pulmonary complications of infection with the human immunodeficiency virus. Am Rev Respir Dis 1989;140:1763-87.

32 Peters BS, Beck EJ, Coleman DG, Wadsworth MJH, McGuiness O, Harris JRW, et al. Changing disease patterns in patients with AIDS in a referral centre in the United Kingdom: the changing face of AIDS. BMF 1991;302: 203-7.

33 Zibrak JD, Silvestri RC, Costello P, Marlink R, Jensen WA, Robins A, et al. Bronchoscopic and radiographic features of Kaposi's sarcoma involving the respiratory tract. Chest 1986;90:476-9.

34 Garay SM, Belenko M, Fazzini E, Schinella R. Pulmonary manifestations of Kaposi's sarcoma. Chest 1987;9:39-43.

35 Gill PS, Akil B, Colletti P, Rarick M, Loureiro C, BernsteinSinger $M$, et al. Pulmonary Kaposi's sarcoma: clinical findings and results of therapy. Am f Med 1989;87:57-61.

36 Fouret PJ, Touboul JL, Maynaud CD, Akoun GM, Roland J. Pulmonary Kaposi's sarcoma in patients with acquired immune deficiency syndrome: a clinicopathological study. Thorax 1987;42:262-8.

37 Miller RF, Tomlinson MC, Cottrill CP, Donald JJ, Spittle MF, Semple SJG. Bronchopulmonary Kaposi's sarcoma in patients with AIDS. Thorax 1992;47:721-5.

38 Mitchell DM, McCarthy M, Fleming J, Moss FM. Bronchopulmonary Kaposi's sarcoma in patients with AIDS. Thorax 1992;47:726-9.

39 Meduria GU, Stover DE, Lee M, Myskowski PL, Caravelli JF, Zaman MB. Pulmonary Kaposi's sarcoma in the acquired immunodeficiency syndrome. Am $\mathcal{F}$ Med 1986; 